\title{
Estudio sociolingüístico de los préstamos en el habla del norte de Marruecos'
}

\author{
Autor: \\ Abdellatif Ghailani \\ Profesor del Departamento de Lengua y Literatura Hispánicas \\ Facultad de Letras y Ciencias Humanas \\ Universidad Abdelmalek Essaadi. Tetuán
}

\section{ACERCA DEL PRÉSTAMO LINGUISTICO}

El término préstamo lingüístico ha dado lugar a mucha variedad de opiniones respecto a la exactitud de su definición. No estoy de acuerdo con quienes optan por hablar de controversias respecto al tema, se trata más bien de diferencia de matices puesto que la idea principal es casi la misma en las distintas definiciones: forma lingüística que recibe una comunidad de otra, que ésta puede adaptarla a sus características o mantenerlas como están en la lengua de origen, ponemos por ejemplo las definiciones que exponen dos autores con una diferencia de tiempo de casi treinta años,

"Elemento lingüístico (léxico, de ordinario) que una lengua toma de otra, el cual implica el enriquecimiento del inventario léxico de una lengua a través del inventario de la otra lengua" Lázaro Carreter (1968)

"Transferencia de un lenguaje a otro de elementos lingüísticos (formas, sonidos e incluso estructuras gramaticales), generalmente en una forma alterada y a veces total o parcialmente traducidos" G. Cannon (1992:34)

El concepto es prácticamente el mismo aunque cambian los puntos de vista de los dos lingüistas. El primero hace un juicio de valor, mientras que el segundo hace hincapié en la adaptación del término a otra lengua.

Aunque el lingüista americano aboga por todos los elementos lingüísticos, en este artículo vamos a tratar solo la forma más frecuente, es decir, el léxico. Para algunos estudiosos limitarse solo a este campo es una visión estrecha del préstamo, es la que se viene llamando la "hipótesis lexicologista", visión más precisa, según mi criterio, y que aborda esa parte de la lengua que es más propicia a trasladarse de una lengua a otra y la que tiende a adaptarse con 
más facilidad a las normas lingüísticas de las comunidades receptoras. En este artículo nos ceñiremos solo a los préstamos que pasan de una lengua a otra, no vamos a tocar otros tipos como el interno, dialectal, etc.

El propio término ha suscitado muchas divergencias respecto a la adecuación o no según el estudio a realizar. Además del que estamos usando en este trabajo, hay quienes prefieren llamarlo extranjerismo, xenismo o neologismo. En muchos casos la palabra extranjerismo adquiere connotaciones negativas de intrusismo que llega para pervertir la lengua, esta es la postura de los considerados "puristas" de la lengua, abogan por usar solo el léxico de la lengua autóctona, o en caso de necesidad de nueva terminología que se recurra a los procesos internos de la misma lengua, la etimología o la lengua de origen, latín por ejemplo, para componer nuevas palabras. No obstante, son muchos los lingüistas que ven el préstamo como una forma de enriquecimiento de las lenguas, como lo hace Lázaro Carreter en la cita de arriba; y, además, como una consecuencia natural de su estado vivo.

Lejos de la comparación botánica de los lingüistas decimonónicos, la lengua es como un ser vivo: nace, se desarrolla, algunas células de su cuerpo mueren y otras nacen, me refiero a las palabras que caen en desuso y otras que aparecen nuevas. Las lenguas tienen vida, cambian al ritmo que cambian los hechos y nuestras experiencias; nadie puede detener este cambio, evolución obligada, por mucho que se aferre al puritanismo y rechazo de los nuevos aportes. En todas la épocas las lenguas han tenido supuestos meticulosos guardianes que consideraban todas las novedades lingüísticas como invasión o vicios que iban a acabar con sus lenguas, No obstante, a lo largo de la historia se ha demostrado que las lenguas son un rio caudaloso que no se le puede cambiar su curso, y menos detenerlo. De intentarlo, siempre termina desbordando y recobra de nuevo su camino. Nada mejor para representar este símil que el aspecto que estamos tratando, los préstamos. Éstos han sido considerados por algunos como vicios innecesarios que deterioran la lengua y se esmeraron por sustituirlos por términos de la propia lengua o echar mano del proceso interno de creación léxica de la lengua materna pero el resultado suele ser el contrario al esperado, el término de nueva creación resulta ser bastante "forzado", en el sentido de que transgrede las normas de la economía del lenguaje, pronunciación no satisfactoria, que hacen que no sea de aceptación por todos los hablantes.

Quizás el término préstamo pueda inducir a error si se entiende tal como se concibe en el mundo de la economía, ceder algo durante un tiempo para recuperarlo más tarde con un valor añadido; o como se entiende a nivel general, dejar algo a alguien que más tarde será devuelto a su dueño. Los préstamos léxicos cuando se adaptan a la lengua receptora se instalan en ella y se perpetúan en el tiempo mientras viva el concepto que designan. Por lo tanto, este tipo de palabras que llegan como neologismos pueden tener la misma suerte que las autóctonas: permanecer para siempre en la lengua de destino, convivir con otro término de la lengua autóctona o con otro préstamo de otra lengua distinta ${ }^{2}$, o perderse cayendo en desuso.

La razón de ser del préstamo se impone por mera necesidad de los hablantes de una lengua para referirse a un determinado concepto que ha sido de reciente inclusión en sus vidas y sus experiencias y que su lengua no posee el significante adecuado para nombrarlo. Por lo tanto, el primer portador de un significado es también el que lleva consigo el término correspondiente para más tarde ser adoptado por todos los hablantes de una comunidad lingüística. Adopción 
que se realiza por imitación a quienes lo introdujeron por primera vez y más tarde a los hablantes habituados a tal instrumento u objeto, en definitiva concepto, hasta llegar a generalizarse para dar lugar a una innovación lingüística, concretamente léxica en este caso, que tendrá como consecuencia final el cambio lingüístico. Al respecto, afirma E. Coseriu (1973:68-110)

"El cambio lingüístico (cambio en la lengua) es la difusión o generalización de una innovación, o sea, necesariamente, una serie de adopciones sucesivas. Es decir que, en último análisis, todo cambio es originariamente una adopción"

La diferencia que se ha hecho siempre entre préstamo y neologismo radica especialmente en el carácter imitativo del primero y el creativo del segundo. La diferencia no es tan clara como afirman algunos autores como R. Gusmani (como se cita en Gómez 1988) el préstamo no es en rigor un aspecto de la creatividad de la lengua, pero tampoco se le puede relegar a un estatus de mera imitación y adopción de modelos extranjeros. K.A. Goddard (1977:109-112) elimina aún más la distancia entre los dos términos: desde una perspectiva estrictamente lingüística, el préstamo es un recurso neológico como cualquier otro, ya que comparte el mismo proceso diacrónico de innovación y posterior difusión. La misma tendencia siguen varios autores entre los que sobresalen J.C. Corbeil y S.S. Morgana. Desde mi punto de vista, esta similitud respecto al aspecto creativo del préstamo la aplicaría únicamente cuando éste se adapta, y se le aplica cuando es necesario, las normas internas de la lengua receptora y sufre modificaciones que afectan bien a su estructura fónica, semántica o morfosintáctica.

Cuando un préstamo se asienta en una nueva lengua y es asimilado por todos los hablantes, a lo largo del tiempo lo consideran como una palabra más de su bagaje léxico y le otorgan todo el valor del que gozan las palabras formadas por el mecanismo interno de la lengua materna, es decir, se pierde por completo la noción de término importado de otra lengua ${ }^{3}$. Los préstamos son un recurso que solventa carencias lingüísticas y enriquece al mismo tiempo. Es consecuencia del contacto de culturas y sociedades, siempre unas han influenciado a otras y han dejado esa huella de convivencia, no hay nada más que ver la cantidad de arabismos en el castellano; hispanismos y galicismos en la variedad dialectal del árabe marroquí, anglicismos en el francés e hispanismos en el inglés americano por poner unos ejemplos.

\section{LOS HISPANISMOS, SEÑAS DE IDENTIDAD LINGÜÍSTICA}

Para una buena contextualización del tema que se abordará en este artículo es preciso dejar bien aclarados los principales puntos que se van a tratar, su situación geográfica, datos históricos y las características lingüísticas de la zona a estudiar. De no hacerlo así podríamos dejar lagunas que dificulten la comprensión de más de un aspecto.

Marruecos a lo largo de la historia, como el resto de los países mediterráneos, ha sido lugar de asentamiento y tránsito de muchas culturas por razones diversas, bien para invadirlo, colonizarlo, para refugiarse, para mejorar la situación socioeconómica, usando como lugar de estancia temporal para trasladarse a otro país, bien para formarse o para hacer negocios. Estas estancias, independientemente de su duración siempre han motivado cambios tanto en la población autóctona como en los nuevos visitantes, cambios causados por el contacto de personas pertenecientes a sociedades distintas que se han visto obligados a convivir y por lo tanto influenciarse. Es cierto lo que afirman algunos especialistas que no se trata de lenguas en contacto sino culturas en contacto. Como es natural, toda relación o trato se ha de realizarse 
con la lengua, uno u otro, según las circunstancias, es obligado a aprender el código con que se comunica su interlocutor para poder relacionarse con él.

El contacto de dariŷa marroquí y el español data de hace varios siglos atrás, podemos remontarnos a los primeros momentos de la conquista de Al Andalús por parte de los Almorávides hasta la expulsión de los moriscos y su asentamiento en Marruecos. Pero la época que interesa para nuestro estudio es a partir del S. XIX, y en especial el S.XX, concretamente desde 1912,

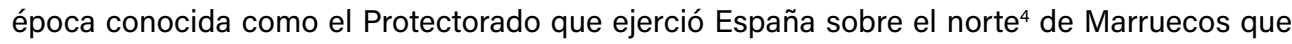
culminó en 1956 con la Independencia del país norteafricano. Respecto a la influencia que tuvo esta época en el cambio lingüístico de la zona colonizada ha sido mucha relevancia en el sentido de que en un periodo menos de cincuenta años la población autóctona llegó a dominar y usar la lengua española con naturalidad; los que menos la entendían bastante bien. Además, lo que más nos interesa para este estudio, es el inmenso número de préstamos que se importaron en todos los sectores.

Parece obvio la llegada de nuevos términos teniendo en cuenta que han sido motivados por la llegada de nuevos artificios y utensilios que los autóctonos desconocían, pero lo más interesante es que se importaron vocablos de la vida cotidiana que pasaron a formar parte del bagaje léxico de toda la población, hecho que no sucedió de forma tan marcada en la zona ocupada por los franceses. Esto se debe a cómo se desarrolló la colonización en una y otra zona. Francia, potencia colonizadora, rica y con mayor ambición expansionista, mantenía con los habitantes de la zona ocupada las relaciones propias de colonizador y colonizado, lo que hizo que las aportaciones e innovaciones, entre ellas la más importante, la lengua, alcanzara, en un principio, solo a las clases altas de la sociedad autóctona, solo ésta tenía la posibilidad de mantener contacto con los franceses. Del país galo se trasladaron a Marruecos los auténticos colonizadores: militares, empresarios y misioneros.

En cambio, en el norte sucedió todo lo contrario, las relaciones eran a todos los niveles de la estructura social, desde las más castigadas económicamente hasta las más acomodadas, lo que dio lugar a una sociedad heterogénea donde se convivía sin complejos. El grueso de españoles emigrados al norte de Marruecos lo formaba la clase baja que se trasladó al país vecino en busca de un futuro mejor. No hay que olvidar que en aquel entonces la provincia de Cádiz, sobre todo las poblaciones de Algeciras y la Línea de la Concepción eran las más pobres de Europa. Entre los españoles llegados al norte de Marruecos no había solo militares y empresarios, había pescadores, albañiles, camareros, reparadores de calzado, vendedores ambulantes, etc. Tanto los norteños como los españoles estaban obligados a convivir y a relacionarse entre sí, y no hay convivencia y entendimiento posible si no hay una lengua común usada por las dos partes, hecho que se demuestra en la cantidad de hispanismos que pasaron a formar parte de la variedad usada por todos los estamentos sociales de esta zona.

Las ciudades sobre la que vamos a desarrollar la investigación son Tetuán, Larache y Tánger, ubicadas en la zona occidental del norte, conocida por región de Yebala frente a la oriental o región del Rif, donde se encuentran las provincias de Alhucemas y Nador, limítrofe con Melilla, de población netamente beréber. El primer diferenciador entre las dos zonas colonizadas por España es la lengua al tratarse de dos etnias distintas, la primera es arabófona mientras que la segunda es berberófona, cuya lengua materna es el tamazig, conocida también por tarifit, 
la lengua hablada en la calle y en el núcleo familiar, el medio con que se comunican los rifeños entre sí.

Los neologismos ${ }^{5}$ que empezaron a usar los habitantes del norte de Marruecos hacían referencia a aspectos generales u ordinarios de la vida. Se introdujo no solo sustantivos, nombres de cosas, sino también algunos verbos sobre todo en argot de las clases marginales como chupar [ĉopar], aprovechar [probeĉár] ${ }^{6}$, jalar [xalár], etc., e incluso algunas partículas conjuntivas como pero [píro] y porque [purkí]. Algunos de los nuevos vocablos, como los citados, tenían sus correspondientes en darîya pero han llegado a convivir hasta el día de hoy sobre todo en la población joven y hombres de un nivel de instrucción bajo. Merece un especial atención la aportación de nuevas técnicas y oficios desconocidos hasta el momento que adoptaran una serie de préstamos exclusivos de aquellos que tenían contacto con dichos profesionales y que no se podían oír en boca de todos los marroquíes del norte, pongamos por ejemplo los términos tapa (carnicería), tas, quilla, terraja, fundido, diodo, estrobo y cigüeñal, estos vocablos pertenecen a determinados sociolectos y jergas profesionales para dar más precisión y especificación a los sectores donde se usan, son muy frecuentes entre los miembros de cada gremio y son insustituibles por otros términos del habla autóctona.

Tomando como ejemplo las tres primeras palabras (tapa, tas y quilla), las comunidades de carniceros, chapistas de automóviles y marineros del norte de Marruecos poseen estos vocablos específicos para designar exclusivamente a "la carne corresponde al medio de la pierna trasera de la ternera", al "yunque pequeño y cuadrado (...) que usan los hojalateros"; y a "la pieza de madera o hierro que va de popa a proa por la parte inferior del barco (...)" (Drae:1992). Solo esta especificación les permite distinguir tales objetos de las demás piezas de carne, cualquier trozo de hierro y maderos que componen una embarcación. El resto de los hablantes no pertenecientes al gremio se referirán a ellos en árabe diciendo este trozo de carne, esa pieza de hierro o ese madero.

Para la realización de este trabajo hemos escogido seis hombres y seis mujeres de cada ciudad lo que hace un total de treinta y seis informantes teniendo en cuenta las variantes de edad y nivel sociocultural. Con los informantes se ha mantenido una charla relajada de quince minutos sobre su actividad en un día libre en verano. ${ }^{7}$

RECUENTO DE INFORMANTES SEGÚN CARACTERÍSTICAS SOCIOLINGÜÍSTICAS DE EDAD Y NIVEL SOCIOECONÓMICO ${ }^{8}$

\begin{tabular}{lcccc}
\hline & $18-28$ & $29-40$ & $\frac{40-60}{2}$ & $\frac{\text { TOTAL }}{\text { H }}$ \\
\cline { 2 - 4 } & $\mathrm{H}-\mathrm{M}$ & $\mathrm{H}-\mathrm{M}$ & $\mathrm{H}-\mathrm{M}$ & $31-24$ \\
\hline ALTO & $11-06$ & $10-06$ & $10-12$ & $33-37$ \\
\hline MEDIO & $12-12$ & $11-12$ & $10-13$ & $38-38$ \\
\hline BAJO & $12-14$ & $14-14$ & $12-10$ &
\end{tabular}


Como se puede apreciar en la tabla, la frecuencia es bastante alta. Los préstamos que se

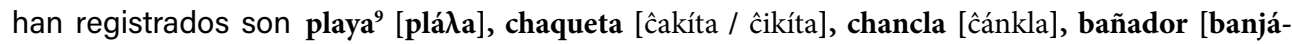
dor], carretera [karatéra], acera [séra], camiseta [kamisíta], botas [bótaț], balón [balón], equipo [kípo], equipación [kipasjón], portería [portería / pórta], árbitro[pítro], tostada [tostáđa], zumo [súmo], mermelada [mirmiláđa], magdalenas [mandalínas], parada [paráđa], bocadi-

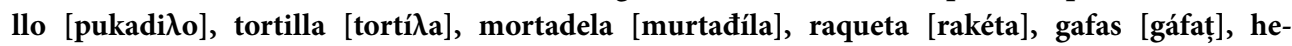
lado 0[láđo], lechería [liciiría], partido [partiđo / parđíđo], falda [fálda], saldo [sáldo], bolso [bólso], mortadela [murtađíla], masaje [masáxe], crema [kríma] y cazadora [kasađóra].

Se demuestra sobradamente que en el habla de todos los estamentos sociales de las poblaciones estudiadas usa un alto número hispanismos como préstamos que fueron introducidos en la época colonial. Este préstamo está muy arraigado en sus hablas. Optar por la razón sociocultural y no la socioeconómica no ha sido algo aleatorio, sino que después de varias averiguaciones he llegado a la conclusión de que tanto las clases más acomodada hasta las más castigadas económicamente usan los términos importados del español en las mismas circunstancias. En cambio, la variante diastrática socioecultural sí que ejerce cierta influencia sobre el léxico de los hablantes de Tetuán y Tánger. Muestra de ello la representa los informantes con un nivel cultural alto que disponen de la posibilidad de alternar el hispanismo con el galicismo o su correspondiente en árabe dependiendo de la situación comunicativa como es el caso de los siguientes términos.

Bañador: se ha registrado 17 veces tanto en hombres como en mujeres. Solo 5 veces como hispanismo en 2 mujeres de Tetuán (49 y 53 años) ${ }^{10}$ con nivel de instrucción alto y 3 en hablantes con nivel bajo. Aparece como galicismo maillot [málo] 8 veces en personas con nivel intermedio y alto cuyas edades están entre 18 y 55 años. Cuatro personas (2 hombres y 2 mujeres) de nivel cultural bajo se han referido a la prenda de baño como short."

Un breve análisis cualitativo de estos datos nos indica que el habla femenina de Tetuán da muestras de su conservadurismo. La gente joven con un nivel de instrucción medio está usando más la forma de galicismo, posiblemente dado a sus conocimientos del francés y también sus relaciones con gente llegada de otras zonas del país donde predomina la influencia francesa. La conclusión que se puede sacar respecto a este término es que está cayendo en desuso, está siendo desbancado por el galicismo y existen indicios de que éste a su vez será superado por el anglicismo. La predilección creciente por la forma inglesa podría radicar en la comodidad de los hablantes que se traducirá en economía del lenguaje. Los hablantes siempre optan por el vocablo más corto o el que supone menor dificultad para reproducirlo. Bastante bien lo aclara Prieto (1967: 165) en esta cita

"Entre todos los semas que sirven para transmitir un mensaje determinado y que, en las circunstancias en que tiene lugar el acto sémico, aseguraron el éxito de éste, el emisor elige aquél que le permite hacer pertinente menos rasgos, es decir, aquél cuyo empleo supone que se suministra al receptor una cantidad menor de indicación significativa" (Prieto, 1967: 165).

Se afianza más el binomio comodidad economía en el anglicismo short por la brevedad en la pronunciación. De las tres posibles a alternativas, hispanismo, galicismo y anglicismo, se escoge este último por suponer menos coste. Además, se trata de un préstamo que abarca 
más de un significado que es uno de los motivos que hace que sea el término preferido para la mayoría de los hablantes; respecto a la repercusión del significado, J. C. Moreno Cabrera (2002: 8) afirma que "el hecho de que las palabras más usadas tengan un significado más general que las menos usadas, también general a las lenguas humanas, procede igualmente de este principio". En este caso la economía es tanto en el significante como en el aspecto sémico. En el mismo artículo, el autor afianza la idea de que queremos comunicar con los mínimos recursos posibles, es decir, que suponga el mínimo coste posible cuando dice que si hay dos formas de expresar lo mismo, una más complicada que otra, se tiende a optar por la que exige menos esfuerzo.

La tendencia creciente a todos los niveles es la sustitución de muchos hispanismos por términos del francés debido a razones demográficas y socioculturales. Cada vez se escuchan menos las voces mermelada y magdalena, censadas 4 y 6 veces respectivamente en nuestra encuesta, donde lo hicieron como hispanismo en 1 y 3 veces, y el resto de las reproducciones han sido galicismos, confiture y madeleine. Quienes optan a veces por sustituir un préstamo español por su homólogo árabe suelen ser la mayoría de las veces hombres mayores de 50 años y con nivel de instrucción alto como sucede con los vocablos gafas y lechería, se registraron 5 y 6 veces respectivamente, de las cuales 2 veces se reprodujeron las palabras de dariŷa correspondientes, menádar y melbana.

El habla de los habitantes del norte de Marruecos se encuentra plagada de préstamos, en su mayoría hispanismos que con el paso del tiempo están sufriendo modificaciones, en desuso unos y surgiendo otros, pero lo que más llama la atención es su sustitución por los galicismos bien importados por los habitantes de ciudades que pertenecieron a la zona de ocupación francesa, bien por los norteños que se trasladan a esta zona por razones laborales o académicas y que vuelven a su tierra aportando las novedades lingüísticas. Estas y otras modificaciones no son más que muestras de que las lenguas son vivas, cambian conforme avanza la sociedad y están lejos del estatismo con que se las quiere pintar a veces.

Otro campo donde abundan los hispanismos es el de los oficios, materiales y técnicas que se introdujeron en el norte de del país con la llegada de los españoles. Aportaciones que afectaron a todos los sectores, incluso los tradicionales como la agricultura, panadería, carnicería, pesca, etc. sufrieron grandes cambios como consecuencia de la modernización. El arraigo de las palabras españolas es tan profundo que muchos, personal del gremio y ajenos a él, no las conciben como préstamos sino como parte del léxico de su lengua materna. No obstante, estos hispanismos están corriendo la misma suerte que los de la vida cotidiana que usa el resto de la población, muchos están siendo reemplazados por galicismos, aunque sí es verdad que de vez en cuando surge algún que otro como consecuencia de la permanente modernización de algunos sectores tecnológicos, la llegada periódica de un gran número de emigrantes afincados en España y la cercanía de Ceuta y Melilla. 


\section{BIBLIOGRAFÍA}

- Cannon, G.( 1926): La pensé et la langue, Paris, Masson.

- Coseriu, E. (1973): Sincronía, diacronía e historia: el problema del cambio lingüístico, Madrid, Gredos.

- Guamani, R. (1983): saggi sull'interferenza lingüística, volumen secondo, Florenzia, Casa Editrice Le Lettere.

- $\quad$ Corbeil, J. (1971): "Aspects du problème néologique", La Banque des Mots, 2, 123-136.

- Alarcos LLorach, E. (1992): “Consideraciones sobre el neologismo", en FUNDACIÓN EFE El neologismo necesario, Madrid, EFE, 17-29.

- Fernández, S.J. (1982): Neología y neologismo en español contemporánero, Granada, Don Quijote.

- $\quad$ GÓMEZ, C. Juan (1998): El préstamo lingüístico (conceptos, problemas y métodos), Valencia, Universidad.

- Guerreo, R. G. (1995): Neologismo en el español actual, Madrid, Arcos Libros.

- Haensch, G. (1975a): "El préstamo lingüístico en el lenguaje coloquial y en las jergas", en Filología y Didáctica Hispánica. Festschrift Scheneider, Hamburgo, 115-130.

- Lázaro Carreter, F. (1977): Diccionario de términos filológicos, Madrid, Gredos.

- Labov, W. (1983): Modelos sociolingüísticos, Madrid, Cátedra.

- Martínez, C. E (1977): "La neología fuente de variedad léxica en español", Anuario de la facultad de Filología de la Universidad de Barcelona, 393-401.

- Moreno, C. JC (2002): "el motor de la economía lingúística: de la ley del mínimo esfuerzo de la automatización retroactiva". Revista española de Lingüística, 32,1, pp. 1-32. Morgana, S.S.(1981): La parole nuove, Bolonia, Zanichelli.

- Nañez, E. (1973): La lengua que hablamos, creación y sistema, Santander.

- Prieto, L. j: (1967): Mensajes y señales, Barcelona, Seix Barral-

- Vallejo, A. P. (1986):" El préstamo semántico: algunos problemas", Anuario de Lingüística Hispánica, II, pp. 216-276, Valladolid, Universidad.

\section{NOTAS}

1 A partir de ahora lo vamos a llamar dariya, es el nombre con que se conoce la variedad dialectal, derivada del árabe, hablada en Marruecos.

2 En estos casos se trata de la superposición de un préstamo por un neologismo que a la postre se convierte también en préstamo que conviven los dos o termina por desplazar el primero. Esta situación la vamos a encontrar con frecuencia en la zona que estamos estudiando debido al contacto de tres lenguas, árabe, español y francés.

3 Viene a colación la siguiente anécdota: cuando estaba encuestando a un miembro bastante respetado en el gremio de la carnicería sobre los términos con que se denominan las partes del ganado vacuno una vez despiezado, se refirió a uno de los huesos de la pata del animal y me dijo tal hueso lo llamamos caña y en árabe tuétano. Esto refleja una integración absoluta del término en la lengua materna de los hablantes del norte de Marruecos debido al uso constante durante un largo tiempo Debemos tener en cuenta que cuando hablamos del norte de Marruecos (la zona ocupada por España) solo nos referimos a la franja mediterránea más las ciudades de Larache y Alcazarquibir, no se trata del norte geográfico que abarca otras ciudades más que fueron ocupadas por Francia.

5 Uso aquí el término neologismo es su sentido estricto, es decir, palabra nueva, que tras su adaptación y asimilación por la sociedad de acogida, se llamará préstamo 
6 Los verbos aprovechar y chupar se usan con el significado de aprovecharse de alguien; mientras que jalar significa comer. Este último es usado solo por la población masculina joven y/o marginal. Está cayendo en desuso.

7 No se trata del estudio de ningún gremio en concreto ni de tecnicismo. Éstos serán analizados en trabajos posteriores.

8 Los datos de la tabla indican el número de veces que se han reproducido los hispanismos durante la conversación. Se ha computado también las veces que se ha repetido.

9 Junto a cada préstamo va su transcripción fonética que refleja los cambios que sufre como consecuencia de la influencia de las reglas y normas lingüísticas que rigen dariŷa marroquí.

10 Las dos señoras son licenciadas y tiene un buen dominio del árabe clásico y muy buenas nociones de francés por lo que podían haber reproducido el préstamo en forma de galicismo.

11 El anglicismo short se está generalizando, se usa cada vez más para referirse a cualquier tipo de pantalón corto, tanto de baño como de vestir o deportivo

\section{CURRICULUM VITAE. ABDELLATIF GHAILANI}

Licenciado en Letras hispánicas. Facultad de Letras de Tetuán, 1987. Licenciado en Filología Española. Facultad de Filosofía y Letras de Granada, 1991. Curso de Adaptación Pedagógica (C.A.P.). Universidad de Granada, 1997. Doctorado en Filología Española (Lingüística): “El español hablado en el norte de Marruecos". Universidad de Granada. 